\title{
Exploring service climate and employee performance in multicultural service settings
}

Purpose - This paper introduces a new conceptual model that incorporates internal service quality as a mediator between service climate and employee performance and two personal cultural orientations (independence and interdependence) as the moderators of these relationships. Design/methodology/approach - An online survey of 353 employees representing 19 different nationalities, working in 18 branches and offices of a multinational Business-to-business (B2B) civil engineering services firm, spread across 14 countries.

Findings - All the hypotheses are supported. Specifically, internal service quality mediates the influence of service climate on employee performance and these relationships are stronger for employees with relatively higher interdependent (vs. independent) cultural orientations.

Research limitations/implications - This paper uses data collected from the employees in a single B2B firm in one industry (Civil Engineering Services) and focuses on a few key variables, which may restrict the generalizability of its findings.

Practical implications - Our findings highlight the importance of cultural factors in building a service climate in multinational service organizations to help their employees work more effectively and efficiently with their colleagues from diverse cultural backgrounds.

Originality/value - This study clarifies the relationships among service climate, internal service quality and employee performance, by showing that internal service quality mediates the influence of service climate on employee performance.

Keywords - business-to-business services, independence, interdependence, internal service quality, service climate, service-profit chain

Paper type - Research paper 


\section{INTRODUCTION}

Despite a significant overlap in the conceptual and empirical domains of the service climate construct and the service-profit chain framework, there is hardly any attempt to theoretically integrate these two research streams in order to develop and empirically validate a comprehensive model of service climate (Bowen and Schneider, 2014; Hong et al., 2013). Hong et al. (2013) address this gap with a model of service climate, its antecedents and outcomes, and a meta-analysis of 58 studies $(\mathrm{N}=9,363)$ to test their hypotheses. However, Hong et al. (2013) focus on the antecedents of service climate (e.g., leadership and HR practices) and do not differentiate between service climate and internal service quality, which may limit the future implications of their results (Bowen and Schneider, 2014). To address this limitation, Bowen and Schneider (2014) present a more comprehensive model with more antecedents of service climate and several moderators (including internal service quality) but they do not provide any empirical evidence about the relationships depicted in their model. As a result, there are still many research gaps and unanswered questions in this area, which we address in this paper.

First, we focus on the lack of consensus about the relationship between service climate and internal service quality. Specifically, Bowen and Schneider (2014) cite Ehrhart et al. (2011) to include internal service quality as a moderator of the link between service climate and customer experience in their model but they ignore the significant correlation of service climate with internal service quality reported by Ehrhart et al. (2011) and with external service quality (Martinez - Tur et al., 2011; Schneider, White and Paul, 1998) that would make its role as a moderator questionable. Moreover, Ehrhart et al. (2011) only studied the service climate at 'branch-level' and internal service quality received from the 'corporate' units, ignoring the 
service provided by branch employees to each other, thus they only provide a partial view of the relationship between service climate and internal service quality. In fact, in a recent study Chen (2013) shows that organization culture and leadership style (which are antecedents of service climate) also have an impact on internal service quality, which suggests that service quality may directly influence internal service quality. Hence, in this paper, we aim to further clarify and explore the relationship between service climate and internal service quality.

Second, we address the lack of clarity on the impact of service climate and internal service quality on employee performance. Specifically, Hong et al. (2013) include service behavior, service performance and service quality as employee outcomes in their theoretical model; however, they study only one of these, service performance, in their meta-analysis. In contrast, Bowen and Schneider (2014) include both in-role behavior and customer-focused organizational citizenship behaviors (OCB) as employee outcomes but they ignore task performance in their service climate framework. Similarly, Chen (2013) do not study the impact of internal service quality on any other employee outcomes and Ehrhart et al. (2011) do not include any employee outcome and only study the impact of service climate on external service quality. Moreover, all these studies use employees' self-assessment of their performance that may be prone of common method bias and demand effects. We address all these concerns by exploring the mediating role of internal service quality in the influence of service climate on employee performance and by using supervisors' assessment of employee performance as the outcome variable to avoid the problems of common method bias and demand effects.

Third, workplaces in service organizations around the world are becoming culturally diverse and this poses serious challenges in creating and managing an appropriate service climate with high levels of internal and external service quality (Sharma, Tam and Kim, 2009, 2012, 
2015). Moreover, prior research shows that cultural values of service employees may affect their job satisfaction and quality of interaction with each other (Carroll and Harrison, 1998; Testa and Mueller, 2009). However, there is hardly any research on the role of cultural factors on the relationships among service climate, internal service quality and employee performance. Hence, we need to understand how the cultural values of employees from diverse cultures may impact the process by which service climate (SC) affects internal service quality (ISQ) and employee performance (EP) but there is hardly any research on this important topic. We address this gap by including two personal cultural orientations, independence and interdependence (Sharma, 2010), as moderators of the SC $\rightarrow$ ISQ and ISQ $\rightarrow$ EP links in our model.

Finally, we address the lack of research on the role of service climate and internal service quality in multicultural Business-to-business (B2B) service organizations. Specifically, prior research on service climate generally focuses on business-to-consumer (B2C) service firms in mono-cultural settings (Hong et al., 2013), such as retail banking in Northeastern US (Schneider, 1973, 1980, 1990; Schneider et al., 1998), retail financial services firm in the US (Schneider, Wheeler and Cox, 1992) and Jamaica (Ehrhart et al., 2011), supermarkets in Eastern US (Schneider et al., 2005) and international tourist hotels in Taiwan (Chen, 2013). However, it is not clear if their findings would be applicable to B2B service firms in multicultural settings. We address this gap by using a large multinational B2B civil engineering firm with ongoing projects and offices in 45 countries around the world and 4,100 employees, as our research setting.

In the next section, we review past literature on service climate, internal service quality, employee performance and personal cultural orientations, to identify the four research gaps mentioned above. We then address these gaps by developing our conceptual model and specific hypotheses about the relationships among these variables. Next, we describe our large-scale 
study conducted in 18 branch offices of a multinational B2B civil engineering firm, covering 14 countries and employees with 19 different nationalities. We then analyze our data using the recommended mediation (Iacobucci, Saldanha and Deng, 2007) and moderated mediation (Preacher, Rucker and Hayes, 2007) analyses. Finally, we discuss our findings, their conceptual contribution and managerial implications with some limitations and directions for future research.

\section{THEORETICAL BACKGROUND AND HYPOTHESES}

\section{Service Climate}

Researchers have studied service climate (SC) for over four decades, beginning with the pioneering work by Schneider (1973) who defines it as the summary perception that customers have of their service provider firm based on specific service-related events. Subsequently, Schneider and his colleagues broaden the scope of service climate by including the employees' perceptions about the events, practices, and procedures as well as the behaviors that are rewarded, supported, and expected, in their respective organizations (Schneider, 1980, 1990; Schneider and Bowen, 1985; Schneider, Parkington and Buxton, 1980; Schneider et al., 1992). Schneider et al. (1998; p. 151) describe service climate as the "employee perceptions of the practices, procedures, and behaviors that get rewarded, supported, and expected with regard to customer service and customer service quality", while Schneider, Macey and Young (2006) define it as simply "the degree to which management emphasizes service quality in all of its activities".

According to Schneider et al. (1998), service climate in an organization has three facets, namely: (i) customer orientation, (ii) management practices, and (iii) customer feedback. The stronger the employees' perception that they are rewarded for delivery quality service; the stronger are their perceptions about the organization's service climate. Service orientation 
attitudes toward customer also contribute to a stronger service climate. Ehrhart et al. (2011) show that service climate at 'branch-level' has a direct impact on external service quality, whereas the quality of service received from 'corporate' functions strengthens the motivational impact of service climate on the delivery of a 'good' (or bad) external service quality. In other words, service climate and internal service quality jointly affect external service quality but more empirical work may be needed to validate these findings (Ehrhart et al. 2011).

\section{Internal Service Quality (ISQ)}

Internal services are defined as "services provided by distinct organizational units or the people working in these, to other units or employees with the organization" (Stauss, 1995). The idea of internal services originated from the concept of internal marketing that involves viewing employees as internal customers and jobs as internal products (and, services) that satisfy the needs and wants of these internal customers while addressing the objectives of the organization (Berry, 1981; Grönroos, 1981). Following the pioneering work by Berry and Grönroos, internal marketing is recognized as a key element of the marketing strategy, especially for service firms as evident in models such as the services marketing triangle (Kotler and Armstrong, 1991). However, most of this discussion remained conceptual, with researchers asking for greater attention to internal customers and their satisfaction to help them perform better (Feldman, 1991; George, 1990; Grönroos, 1985; Piercy and Morgan, 1991; Rafiq and Ahmed, 1993).

Heskett et al. (1994) addressed these calls with their service-profit chain (SPC) framework, which describes a chain of relationships beginning with internal service quality (ISQ) resulting in employee satisfaction, employee retention and productivity, which in turn create external service value, customer satisfaction and loyalty that ultimately lead to revenue growth 
and profitability. In fact, Heskett et al. (1994; p.174) described internal service quality as the “quality of work life itself" and "a visible expression of an organization's culture, one influenced in important ways by leadership". They also offered many antecedents of ISQ, including, i) workplace design, ii) job design, iii) employee selection and development, iv) employee rewards and recognition, and v) tools for serving customers. Although only a few researchers have managed to empirically validate all the proposed relationships in the service-profit chain (e.g., Homburg, Wieseke and Hoyer, 2009; Kamakura et al., 2002; Loveman, 1998), businesses all over the world continue to use service-profit chain to improve their performance due to its popularity and intuitive appeal (Heskett, Sasser and Wheeler, 2013).

Following the growing popularity of Service-Profit Chain as a management philosophy, researchers tried to test its various stages empirically but they were stymied by a lack of wellestablished measures for constructs such as internal service quality. Early attempts in this regard simply used the popular SERVQUAL model to operationalize ISQ and many could replicate its five-dimensional structure - Reliability, Assurance, Tangibles, Empathy, Responsiveness (e.g., Edvardsson, Larsson and Setterlind, 1997; Frost and Kumar, 2000; Kang, James and Alexandris, 2002; Young and Varble, 1997). However, others found many new dimensions in addition to the original five, such as flexibility, confidentiality, professionalism and preparedness (Reynoso and Moores, 1995) or credibility, competence, courtesy, understanding and access (Brooks, Lings and Botschen, 1999; Lings and Brooks, 1998).

Notwithstanding the above, some researchers began with a clean slate and tried to develop a measure for ISQ independent of SERVQUAL. For example, (Bruhn, 2003) developed 'Internal Service Barometer' (ISB) with twelve dimensions, namely, i) competence, ii) reliability, iii) accessibility, iv) friendliness, v) reaction speed, vi) time required to provide the service, vii) 
flexibility, viii) customization, ix) added value generated, $x$ ) cost-benefit ratio, $x i)$ transparency in services, and xii) cost transparency. More recently, Jeng and Kuo (2012) have developed a scale with eighteen dimensions based on Chinese subculture characteristics in Taiwan, Singapore and China, including assistance, attitude, communication, competence, confidentiality, delivery value, harmony, please supervisor, preparedness, promise, processes, relationship, responsible, tangibles, trust, value customer, vendor management and work loading.

\section{Service Climate and Internal Service Quality}

Despite the popularity of service climate and internal service quality constructs in contemporary service research there are still many unanswered questions about how these two constructs relate with each other. First, Schneider and his colleagues developed the service climate construct well before the term internal marketing, internal customer or internal service quality were introduced, hence it is not clear how these concepts fit within the overall service climate framework. Second, from the definition of service climate (Schneider et al. 1998; p.151), it is not clear if internal service quality may lead to the development of service climate or vice versa. This picture is further clouded by past research showing 'inter-department service' resulting in service climate over time (Schneider et al., 1998) and recent claims about the moderating role of internal service quality on the relationship between service climate and external service quality despite a strong correlation between service climate and internal service quality (Ehrhart et al., 2011).

Schneider et al. (2005) provide some clarity about the above mixed picture by showing that other constructs, such as service leadership, may drive both service climate and internal service quality by using leadership communication and modelling behavior. More importantly, Schneider et al. (2005) show that employees show greater customer-focused OCB in units with a 
stronger service climate because in such units service quality is important. In other words, units with a strong service climate are more likely to use modeling and positive reinforcement to encourage employees to provide high quality of service to each other, set goals for customer satisfaction, plan for making service happen, and most importantly, ensure that employees have the assistance, tools, and resources necessary to deliver service quality (Ehrhart et al., 2011).

Based on the above, it seems clear that in a cross-sectional perspective, good service climate would encourage employees to provide good quality of service to each other and this would lead to a higher level of overall internal service quality (Mokhtaran et al., 2015). However, it may not be possible to build a good service climate simply with high internal service quality because it would require other inputs such as leadership, management supports and reward system (Schneider et al., 2005). Moreover, building service climate using internal service quality and these other ingredients may take a long time to evolve (Schneider et al., 2006; Schneider et al., 1998). Finally, Heskett et al. (1994) also identify many drivers of internal service quality, which include workplace and job design, employee selection and development policies, employee rewards and recognition processes as well as tools for serving customers, all of which actually constitute service climate (Schneider et al. 1998). Hence, it is service climate that drives internal service quality in a cross-sectional perspective. Therefore, we hypothesize as follows:

H1: Service climate has a positive effect on internal service quality.

\section{Employee Performance (EP)}

Prior research on service climate examines its influence on a wide range of employee outcomes, beginning with job satisfaction (Schneider et al., 1980), employee dissatisfaction, frustration and turnover (Schneider, 1980; Schneider and Bowen, 1985), role ambiguity and conflict (Schneider 
and Bowen, 1985) to customer-focused OCB (Schneider et al., 2005; Schneider et al., 2006), employee attitudes and service performance (Hong et al., 2013). Similarly, studies on internal service quality explore its impact on employee satisfaction, retention and productivity (Heskett et al., 1994; Loveman, 1998), job satisfaction (Chiang and Wu, 2014; Pantouvakis, 2011) and job performance (Nazeer, Zahid and Azeem, 2014). However, most of these studies use a singlesource (i.e., the employees) to collect their self-reported subjective assessments of their own jobrelated attitudes, satisfaction, performance and behavioral intentions. Hence, it is not clear if service climate or internal service quality would actually have a significant impact on the employee performance. More importantly, there is no consensus about which of these variables would mediate or moderate each other's influence on employee performance.

Prior research distinguishes between two types of employee performance; task performance that is generally role-prescribed and contextual performance that tends to be more discretionary (Motowidlo and Van Scotter, 1994). Specifically, task (or, in-role) performance reflects how well an employee performs the duties required by the job; and contextual (or, extrarole) performance relates to an employee's actions that help shape the social and psychological context of an organization (Borman and Motowidlo, 1997). In the internal service context, task performance would refer to all the activities directly related to the employees' roles (e.g., design, construction, maintenance etc.) and contextual performance may include all the support activities provided by them to their counterparts in other parts of the firm (Zhang et al., 2011). However, there is hardly any research on the impact of service climate and internal service quality on employees' in-role and extra-role service behaviors towards their internal customers. In this paper, we include both in-role and extra-role behaviors in addition to an overall assessment by the supervisors, to measure employee performance in an objective manner. 
In contrast, there is substantial evidence in the extant research on service-profit chain framework (Homburg et al., 2009; Hong et al., 2013; Kamakura et al., 2002; Loveman, 1998; Silvestro and Cross, 2000) which shows that internal service quality has a positive effect on employee satisfaction. Similarly, research in organization behavior and human resources areas also clearly shows that satisfied employees perform better in their jobs and provide a superior quality of service (Chiang and Wu, 2014; Nazeer et al., 2014). Based on these findings, we argue that besides affecting employee satisfaction and loyalty, internal service quality would also have a significant direct effect on employee performance because a higher level of internal service quality would make their jobs easier and allow them to deliver a higher quality of service. Therefore, we hypothesize as follows:

H2: Internal service quality has a positive effect on employee performance.

\section{Mediating Role of Internal Service Quality}

Ehrhart et al. (2011) show that internal service quality received from corporate units moderates the influence of branch-level service climate on the external service quality received by customers at the branch-level. We argue that such a result would be more likely in those organizations where the branch-level service climate may be relatively independent of the internal service quality received from the corporate units, which was probably the case in the Caribbean financial services firm and its 37 retail branches used by Ehrhart et al. (2011). However, in most organizations the branch offices and the corporate units may share a similar service climate, hence the internal service quality provided by them to each other is likely to be highly correlated with the overall service climate. In fact, even in Ehrhart et al.'s (2011) study, they found a fairly high correlation $(r=.36, \mathrm{p}<.05)$ between internal service quality provided by corporate units and the branch-level service climate, which puts into question the role of internal 
service quality as a moderator because ideally the independent and moderator variables should be uncorrelated with each other for a clear interpretation (Baron and Kenny, 1986; p.1174).

Hence, it is interesting to note that an earlier longitudinal study Schneider et al. (1998) found a positive correlation between inter-department service and service climate, based on which they argued that it is the service-oriented policies and practices that produce the service climate. However, Schneider et al. (1998; p.159) admit that they did not directly testing this proposition. Similarly, in another study Schneider, Salvaggio and Subirats (2002) argue that it is the strength of the service climate that moderates the relationship between employee perceptions of service climate and customer satisfaction experiences and they found partial support for this hypothesis using both a concurrent and a predictive (3-year) test across 118 branches of a bank.

In this paper, we aim to reconcile these somewhat divergent findings reported by Schneider et al. (1998) and Ehrhart et al. (2011) by differentiating between the cross-sectional and longitudinal perspective of service climate used by them respectively. Specifically, we argue that the developmental or longitudinal approach used by Schneider et al. (1998) focused on the process by which organizations develop service climate, according to which work facilitation and inter-department service provide a foundation for global service climate that is enacted into an actual service climate as a function of service practices (customer orientation, managerial practices, and customer feedback). In contrast, Ehrhart et al. (2011) seem to take a crosssectional perspective in which branch-level service climate exists independent of internal service quality received from the corporate units and hence it makes sense to treat this internal service quality as a moderator rather than an antecedent of service climate. In other words, both these studies are looking at service climate and internal service quality from two opposite sides and this would probably explain their seemingly divergent results. 
We acknowledge Schneider et al.’s (1998) view that service climate is built on a foundation of various organizational factors that contribute to a culture of customer-centric service orientation. We also agree that service climate reflects employees' perceptions about these practices, procedures, and behaviors about customer service that get rewarded, supported, and expected in their organization. However, we also use Ehrhart et al.'s (2011) cross-sectional perspective to argue that all organizations have some form of service climate that could be good or bad, weak or strong and this in turn would influence the individual employees' attitudes and behaviors in their interactions with both internal and external customers, as reflected by internal service quality and employee performance respectively. Based on the above, we posit that internal service quality would mediate the effect of service climate on employee performance.

H3: Internal service quality mediates the positive effect of service climate on employee performance.

\section{Moderating Role of Personal Cultural Orientations}

Prior research on service climate and internal service quality has generally ignored the influence of national culture or individual cultural values despite substantial evidence about the impact of national culture on organizational culture (Schneider, Ehrhart and Macey, 2013). In this paper, we address this important research gap by exploring the moderating effects of two of these personal cultural orientations (independence and interdependence) on the relationships among service climate, internal service quality and employee performance. We chose these two personal cultural orientations for two reasons. First, these two variables represent the personal level operationalization of the individualism-collectivism dimension in Hofstede's national cultural framework (Hofstede, 1980, 1991, 2001) that explain more variance in employee behaviors compared to the other dimensions such as power distance, masculinity-femininity or long-term 
orientation. Second, using these two personal cultural orientations also help us keep our model simple and parsimonious, especially with all the direct and indirect effects involving the other three variables, namely service climate, internal service quality and employee performance.

Independence (IND): People from individualistic cultures prefer loose ties with each other and they are generally only expected to look after themselves and their immediate family (Hofstede, 2001; p. 225). Such people emphasize independence and prefer to act independently rather than as members of groups due to their strong self-concept and sense of freedom (Hofstede, 1980, 1991, 2001). Sharma (2010; p.790) introduced 'independence', an individuallevel cultural orientation, which is similar to other cultural values such as competence (Bond, 1988), individualism and achievement (Trompenaars, 1993), self-direction and hedonism (Schwartz, 1994), and autonomy (Steenkamp, 2001). Prior research shows that customers from individualistic cultures are more likely to rely on tangible rather than intangible cues from the environment (Mattila, 1999) as well as objective criteria such as reliability, responsiveness and tangibles rather than subjective criteria such as empathy and assurance (Furrer, Liu and Sudharshan, 2000; Mattila, 1999; Mattila and Patterson, 2004). As a result, consumers with higher levels of independence show weaker effect of service quality (a subjective evaluation) on customer satisfaction, perceived value and behavioral intentions (Sharma, Chen and Luk, 2012).

Based on the above, we argue that employees with higher levels of independence are also more likely to be self-driven and less likely to rely on support from their organizations in terms of policies, practices or leadership, hence the presence or absence of a good service climate may not make any significant impact on the level of internal service quality provided or perceived by them. Specifically, in a poor service climate, employees with high independence are likely to take individual responsibility for their actions and take the initiative to provide a high level of 
service quality irrespective of lack of helps from their colleagues in their own or from other departments. In contrast, in a good service climate, employees are likely to help each other and provide a high level of service quality to each other, which may not have any impact on the employees with high independence. Therefore, we hypothesize as follows:

H4a: The positive impact of service climate on internal service quality would be stronger (weaker) for employees with lower (higher) levels of independence.

People with higher levels of independence prefer to act independently rather than rely on their group members and they are more likely to develop greater autonomy and personal achievement due to their strong self-concept and sense of freedom (Oyserman et al. 2002). In view of these distinct characteristics, we argue that employees with higher independence levels are more likely to maintain their 'proactive' and 'positive' attitudes even when faced with poor internal service quality because they would take individual responsibility for their actions and perform their duties irrespective of the level of service quality provided by others. In contrast, high internal service quality may not make a difference to conditions, even though employees are more likely to help and provide high level of service quality to each other, it may not have any impact on the performance of those with high independence as they are willing to work by themselves rather than depend on others. Therefore, we hypothesize as follows:

H4b: The positive impact of internal service quality on employee performance would be stronger (weaker) for employees with lower (higher) levels of independence.

Interdependence (INT): People in collectivistic cultures are integrated into strong and cohesive in-groups, which continue to protect them in exchange for unquestioning loyalty throughout their lifetime (Hofstede, 2001; p. 225). Collectivism is associated with values such as benevolence, tradition, and conformity (Schwartz et al., 2001), cultural inwardness, social 
reliability and morality (Bond, 1988), benevolence and conformity (Schwartz, 1994), and universalism (Smith, Dugan and Trompenaars, 1996). Collectivists see themselves as part of one or more in-groups and are willing to give priority to the goals of their in-groups over their own personal goals (Oyserman et al. 2002). Sharma (2010; p.790) reconceptualizes collectivism as interdependence, a personal cultural orientation that includes "acting as a part of one or more ingroups, a strong group identity, a sense of belongingness, reliance on others, giving importance to group-goals over own individual goals and collective achievement".

Prior research on evaluation of service encounters shows that customers from collectivistic cultures focus more on the subjective aspects such as attitudes and behavior of service employees (Donthu and Yoo, 1998). As a result, consumers with higher levels of interdependence show a stronger effect of service quality (a subjective evaluation) on customer satisfaction, perceived value and behavioral intentions (Sharma, Chen, et al., 2012). Based on this, we argue that employees with high interdependence are also more likely to depend upon their organization and colleagues for support and guidance in order to perform their duties, hence service climate may have a stronger impact on internal service quality for such employees compared to those with lower levels of interdependence. Therefore, we hypothesize:

H5a: The positive impact of service climate on internal service quality would be stronger (weaker) for employees with higher (lower) levels of interdependence.

We also argue that the employees with high interdependence are more likely to see themselves as part of one or more in-groups and be willing to give priority to the goals of these in-groups over their own personal goals (Oyserman et al. 2002). Therefore, in a high service climate, employees with high interdependence may be more eager to help each other and thus 
provide a higher level of internal service quality due to their collectivistic tendency of giving priority to the goals of the in-group rather than their own individual goals. In contrast, in a low service climate, unlike employees with high independence, those with high interdependence may not take the initiative to provide a high level of service quality and instead depend on others to perform their roles and be responsible for providing high internal service quality, a phenomenon known as 'social loafing' (Karau and Williams, 1993). In both these situations, we expect employees with lower levels of interdependence to behave somewhat like those with higher levels of independence although these two are not the opposite of each other. Hence, as follows:

H5b: The positive impact of internal service quality on employee performance would be stronger (weaker) for employees with higher (lower) levels of interdependence.

Figure 1 summarizes all the hypotheses.

$<$ Insert Figure 1 about here $>$

\section{METHODOLOGY}

\section{Research Design}

To test all our hypotheses, we used a self-administered questionnaire-based survey to collect data from the employees and supervisors working for a multinational civil engineering firm with branch offices and ongoing projects in 45 countries around the world. This firm provides a wide range of services (e.g., design and engineering, consulting and IT support, research and development, material testing and production technology) to very large customers such as multinational project construction companies and governments. We chose this firm because it represents B2B services in a multicultural setting that is different from the B2C monocultural settings used in prior research on service climate and internal service quality (e.g., Schneider et 
al. 1998; Ehrhart et al. 2011). Therefore, this setting helps us not only replicate these concepts and test their generalizability in a significantly different service environment but also control for any possible confounding factors by using employees of a single company.

\section{Procedure}

We used two questionnaires to collect data from two different sources in two different settings, in order to avoid the common method bias associated with single source, single setting studies. Questionnaire-A was used to collect the data from individual employees working in different departments and branches of the target firm located around the world. Questionnaire-B was used to collect the evaluation of individual employees' performance from their immediate supervisors.

During the initial phase of data collection, we shared both Questionnaires A and B with the Country Managers as well as the Department Heads in all the countries where the target firm has a subsidiary or a branch office, in order to ensure their support for this research project. After getting their approval, survey questionnaires were sent separately to the individual employees (including both office and site staff) and their supervisors by post and these were returned to us in sealed envelopes to avoid any contamination. We planned a sample size of about 400 based on the population size of about 4,100 (total number of employees in the target firm) and a target pvalue of .05 for both continuous and categorical variables (Bartlett, Kotrlik and Higgins, 2001; p.48, Table 1). We managed to get 353 completed sets of both Questionnaire A and B, from participants representing 19 nationalities, working in 18 branches and offices in 14 countries.

\section{Measures}


We adapted well-established scales to operationalize all the variables. Questionnaire A included the six-item global service climate (GSC) scale (Schneider et al., 1998; p. 154, Table 2) and the 12-item internal service quality (ISQ) scale (Bruhn, 2003; p. 1195, Table III), both with sevenpoint Likert-type response formats $(1=$ Very poor to $7=$ Excellent $)$. We also included the sixitem composite service climate (CSC) scale (Schneider et al., 1998; p. 154, Table 2) and the fiveitem independence (IND) and interdependence (INT) scales (Sharma, 2010; p.794) albeit with a different seven-point Likert-type response format $(1=$ Strongly disagree to $7=$ Strongly agree $)$. Questionnaire B was used by the supervisors to evaluate employee service performance (ESP) with four-item scales for in-role (IRB) and extra-role behaviors (ERB) and a single-item scale for overall employee performance (OEP), all adapted from Werner (1994; p.100) and used a sevenpoint Likert-type response format $(1=$ Very poor to $7=$ Excellent $)$.

We also included several demographic variables (gender, education, tenure, job role, experience, operating unit and nationality of respondents) to use these as control variables in our data analysis. In addition, we included four more control variables (country of birth, years outside country of birth, total years of working experience and total year of working overseas) as all these may have an effect on employees' attitudes and behaviors especially if they have worked or stayed outside their home country or country of birth for a long period time. Table 1 summarizes the sample profile in terms of demographics and other characteristics.

$<$ Insert Table 1 about here $>$

\section{DATA ANAYSIS AND RESULTS}

We used the well-established two-step process to analyze our data (Anderson and Gerbing, 1988), by first testing our measurement model to assess the psychometric properties of all the scales 
using confirmatory factor analysis with AMOS 22. Our measurement model shows a close fit with all the fit indices $\left(\chi^{2}=1126.56, d f=799, \chi^{2} / d f=1.41, \mathrm{CFI}=.96\right.$; NFI $=.93, \mathrm{RMSEA}=.043$, SRMR $=.055)$ better than their recommended cut-off values $\left(1<\chi^{2} / d f<3\right.$, CFI $>.95$, NFI $>.90$; RMSEA $<.06$, SRMR $<.08)$. All the factor loadings are higher than .70 and have large and significant $t$-values $(10.82$ - 28.46) with no major cross-factor loadings. All the parameter estimates $(\lambda)$ are significantly different from zero at $5 \%$ significance level that shows a high degree of convergent validity and none of the confidence intervals of the correlation coefficients for each pair of scales ( $\Phi$ estimates) includes 1.0 showing discriminant validity (Anderson and Gerbing, 1988). All the scales are reliable with construct reliabilities (.84 to .96) much higher than .60, the recommended cut-off value (Bagozzi and Yi, 1988). Average variance extracted for each construct (.63 to .71$)$ is greater than .50 and higher than the square of its correlation with each of the other constructs, providing further evidence of convergent validity (Fornell and Larcker, 1981). Table 2 shows the psychometric properties of all the scale items and Table 3 shows the correlations matrix for all the constructs with their composite reliabilities, average variance extracted and descriptives (mean and standard deviation).

$<$ Insert Table $2 \& 3$ about here $>$

Having established the reliability and validity of all the scales, we next used the structural model to test our first three hypotheses (H1-H3) as recommended by Iacobucci et al. (2007; p.153). For this, we first assessed a model with a direct path from the independent variable (global service climate) to the dependent variable (employee service performance) and an indirect path through the mediator (internal service quality). The model shows a good fit $\left(\chi^{2}=334.09, d f=186, \chi^{2} / d f=\right.$ $1.79, \mathrm{CFI}=.98 ; \mathrm{NFI}=.96, \mathrm{RMSEA}=.037, \mathrm{SRMR}=.048)$ with significant path coefficients from global service climate to internal service quality $(\mathrm{H} 1: \beta=.68, \mathrm{p}<.001)$ and internal service 
quality to employee service performance $(\mathrm{H} 2: \beta=.22, \mathrm{p}<.01)$. Hence, $\mathrm{H} 1$ and $\mathrm{H} 2$ are supported. Moreover, the direct path from global service climate to employee performance is not significant $(\beta=.08, p>.31)$. These results suggest the presence of a mediation effect and to ascertain its strength we used Sobel's (1982) z-test as recommended by Iacobucci et al. (2007; p.153). A significant value of $\mathrm{z}$-statistic $(\mathrm{z}=2.65, \mathrm{p}<.01)$ and a non-significant direct path from global service climate to employee service performance $(\beta=.08, p>.31)$ show a complete mediation (Iacobucci et al., 2007). We repeated these analyses with our alternate measures for service climate (composite service climate) and employee performance (overall employee performance). As reported in Table 4, we found significant values of z-statistic in all the cases but the direct path from composite service climate to both the measures of employee performance is also significant, which suggests a partial mediation. Overall, we found evidence of mediation in all the four cases, hence H3 is supported.

$<$ Insert Table 4 about here $>$

Next, we used the method recommended by Preacher et al. (2007) to test our next set of hypotheses (H4-H5) about the moderating effects of independence and interdependence on the mediating role of internal service quality between service climate and employee performance. To do this, we first mean-centered the average scores of all the variables including the independent (global service climate), mediator (internal service quality), moderators (independence and interdependence) and dependent (employee service performance) variables. We then created four interaction terms by multiplying the mean-centered score for global service climate and internal service quality with those for independence and interdependence. We then created a moderated mediation structural model based on Preacher et al. $(2007 ;$ p.194) that includes all the direct and indirect relationships hypothesized in our conceptual model, as shown in Figure 2. 
$<$ Insert Figure 2 about here $>$

We found a good fit for the moderated mediation model $\left(\chi^{2}=470.02, d f=219, \chi^{2} / d f=2.15, \mathrm{CFI}\right.$ $=.97 ; \mathrm{NFI}=.95, \mathrm{RMSEA}=.038, \mathrm{SRMR}=.057)$ with significant path coefficients for all the hypothesized relationships as shown in Table 5. Specifically, we found significant effects of global service climate on internal service quality $(\mathrm{H} 1: \beta=.60, \mathrm{p}<.001)$ and internal service quality on employee service performance $(\mathrm{H} 2: \beta=.20, \mathrm{p}<.01)$. Similarly, the interaction terms, SC * IND (H4a: $\beta=-.16, p<.01)$ and SC * INT $(H 4 b: \beta=.15, p<.01)$ have significant effects on internal service quality, and IND * ISQ (H5a: $\beta=-.21, \mathrm{p}<.01)$ and INT * ISQ (H5b: $\beta=.17$, $\mathrm{p}<.01)$ on employee service performance, in the expected directions. We repeated this analysis with our alternate measures for service climate and employee performance and found similar results, as reported in Table 5. Hence, all our hypotheses are supported.

\section{$<$ Insert Table 5 about here $>$}

To further investigate all the four interactions, we used spotlight analysis by testing additional models for each relationship with the values of the two moderators (independence and interdependence) replaced with values one standard deviation below $(\mathrm{M}-1 \mathrm{SD})$ and above $(\mathrm{M}+$ $1 \mathrm{SD}$ ) their mean values respectively (Aiken and West, 1991; Spiller et al., 2013). As shown in Table 6 , the path coefficients for SC $\rightarrow$ ISQ is significantly higher at $\mathrm{M}-1 \mathrm{SD}(\beta=.69, \mathrm{P}<.001)$ than at $\mathrm{M}+1 \mathrm{SD}(\beta=.53, \mathrm{P}<.001)$ for independence $(\mathrm{H} 4 \mathrm{a})$ and lower at $\mathrm{M}-1 \mathrm{SD}(\beta=.55, \mathrm{P}$ $<.001)$ than at $\mathrm{M}+1 \mathrm{SD}(\beta=.72, \mathrm{P}<.001)$ for interdependence $(\mathrm{H} 5 \mathrm{a})$. Similarly, the path coefficients for ISQ $\rightarrow$ EP is significantly higher at $\mathrm{M}-1 \mathrm{SD}(\beta=.25, \mathrm{P}<.001)$ than at $\mathrm{M}+1$ $\mathrm{SD}(\beta=.13, \mathrm{P}<.001)$ for independence $(\mathrm{H} 4 \mathrm{~b})$ and lower at $\mathrm{M}-1 \mathrm{SD}(\beta=.14, \mathrm{P}<.001)$ than at 
$\mathrm{M}+1 \mathrm{SD}(\beta=.22, \mathrm{P}<.001)$ for interdependence $(\mathrm{H} 5 \mathrm{~b}) . \mathrm{We}$ found similar results with the other measures for service climate and employee performance. Hence, H4-H5 are fully supported.

$<$ Insert Table 6 about here $>$

In order to address any concerns about using respondents from different job roles (e.g. site supervisor, administration, accounts, purchase etc.) affecting our results because the importance of traits such as independence may vary significantly in these different functions, we tested the differences in the average scores of these two variables and the strength of their relationships with each other among the different job roles and found no significant differences $(p>.05)$. Hence, having the participants from different job roles in our sample does not seem to have systematically influenced our results. In addition, concerns may be raised about $42.8 \%$ of our sample having less than 2 years tenure in the target firm because they may not be influenced by the service climate in such a short time or it may be difficult to measure their performance. We addressed this concern by dividing our sample into two groups, one with less than 2 years' tenure and the other with 2 or more years. We than compared the average scores for all the variables as well as tested our path model across these two groups and found no significant differences. Hence, our results appear to be quite robust across the two groups, irrespective of the employees' tenure in their current jobs.

\section{Common Method Variance}

We employed suitable methodological remedies and statistical analyses to diagnose and address common method variance (Podsakoff et al., 2003). We first minimized common method variance by, a) clearly informing and assuring all the participants about the anonymity and confidentiality of their responses, b) using a variety of response formats for all the scales used, and c) collecting 
the independent and dependent variables from two different sources (employees and their supervisors) and using two different questionnaires. Besides these procedural remedies, we also used the single common method factor approach to estimate the method biases at the measurement level and to control the measurement error (Podsakoff et al., 2003). We compared the fit indices between our final measurement model and one in which all the items load on a latent CMV factor in addition to their theoretical constructs to partition the variance for a specific measure into three components: trait, method, and random error. The model with the CMV factor showed a poor fit $\left(\chi^{2}=1828.92, d f=757, \chi^{2} / d f=2.42, \mathrm{CFI}=.92 ; \mathrm{NFI}=.88\right.$, RMSEA $=.068$, SRMR $=.092)$ significantly worse than our final measurement model $\left(\Delta \chi^{2}=\right.$ 702.36, $d f=42, p<.001)$. Hence, most of the variance is explained by the latent factors and common-method variance does not seem to be a problem in our study (Podsakoff et al., 2003).

\section{DISCUSSION}

In this paper, we begin by identifying four specific gaps in the prior research on service climate, including, a) no consensus about the relationship between service climate and internal service quality, b) lack of clarity in the influence of service climate and internal service quality on employee performance, c) no research on the impact of cultural factors on the relationships among service climate, internal service quality and employee performance, and d) lack of research on the role of service climate and internal service quality in multicultural B2B service organizations. Next, we address all these gaps by hypothesizing, a) service climate as a driver of internal service quality, b) internal service quality as the mediator in the influence of service climate on employee performance, and c) independence and interdependence as the moderators of the linkages among service climate, internal service quality and employee performance; and d) using a multicultural B2B services organization as our research setting. 
Using a cross-sectional survey-based research design to collect data from employees representing 19 different nationalities, in 18 branch offices of a multinational B2B civil engineering firm across 14 countries, we found support for all our hypotheses. Specifically, we first show that service climate has a positive effect on internal service quality, which in turn has a positive impact on employee performance. We then use mediation analysis (Iacobucci et al., 2007) to show that internal service quality fully mediates the effect of service climate on employee performance. Next, we use moderated mediation analysis (Preacher et al., 2007) to show that independence has a negative and interdependence has a positive moderating influence on the impact of service climate on internal service quality as well as the impact of internal service quality on employee performance. Finally, we also replicate all these results with two alternate measures of service climate (a global and a composite measure) as well as employee performance (a composite and an overall measure). Our findings make several useful conceptual contributions and also have many important managerial implications.

First, we combine two major research streams in service research, namely service climate (Ehrhart et al., 2011; Schneider et al., 2009; Schneider et al., 1998) and internal service quality (Bruhn, 2003; Johnston, 2008; Kang et al., 2002; Nazeer et al., 2014), to demonstrate that service climate has a direct impact on internal service quality from a cross-sectional perspective. We acknowledge the longitudinal approach used by Schneider et al. (1998) to show that interdepartment service and work facilitation through appropriate policies and procedures may lead to a good service climate over time. However, we also extend limited prior knowledge about the relationship between these two constructs because past research seems to have generally ignored it despite evidence of a strong correlation between these constructs (Ehrhart et al., 2011). We 
also extend the service profit chain model by adding service climate as an antecedent of internal service quality, an idea that is hinted by not explicitly stated by Heskett et al. (1994).

Our findings are also in line with Chen (2013) who shows a significant impact of two key antecedents of service climate (culture and leadership style) on internal service quality, thus suggesting that service climate may directly influence internal service quality. To summarize, we posit that while it may be necessary to have good internal service quality along with a number of other factors to create service climate over time, in a given situation service climate would drive the level of internal service quality in any organization. This is an important conclusion for service organizations because it shows that in order to provide a high level of external service quality, they first need to focus on developing a strong service climate in order to develop a culture of providing a high quality of internal service by its employees to each other. Doing this will go a long way in helping them realize the full potential of their service-profit chain in terms of customer loyalty and profitability, as postulated by Heskett and his colleagues (1994).

In addition to clarifying the relationship between service climate and internal service quality, we also show that internal service quality partially mediates the impact of service climate on employee performance. We validate these results using alternate measures for both service climate and employee performance, hence this is quite a robust finding and it extends prior research that explores the link between service climate and employee performance. Moreover, we collected the assessment of employee performance from their supervisors using a separate questionnaire than the one used for the employees to overcome common method bias suffered by studies using the same questionnaire to collect the employees' self-assessment of their own performance (Chiang and Wu, 2014; Nazeer et al., 2014; Pantouvakis, 2011). 
The findings about the mediating role of internal service quality resonate with other researchers showing that it is not enough to have a positive service climate for large service organizations because it may not have a direct impact on individual employees' performance as reflected by their in-role and extra-role behaviors (Bowen and Schneider, 2014; Miao et al., 2015). Instead, firms would need to translate their service climate into a high level of internal service quality by ensuring smooth exchange of information and materials across different departments and regular coordination and cooperation across the traditional departmental boundaries, in order to improve employee performance. In addition, the typical vertical authority-based reporting systems may not be suitable for the relatively more horizontal organization structures that are prevalent these days.

Finally, this is also possibly one of the first studies to investigate the impact of personal cultural orientations on the links among social climate, internal service quality and employee performance. We found consistent evidence that the level of independence in an employee helps them overcome the negative impact of a poor service climate and lower levels of internal service quality; whereas the level of interdependence has exactly the opposite effect. Besides extending our knowledge about cultural differences in internal service encounters, these findings also have major implications for global and multinational service organizations that employ people with diverse cultural backgrounds. Specifically, service firms in the traditionally independent cultures such as in North America and Western Europe, may need to improve their service climate and internal service quality if they are increasingly hiring employees from the interdependent cultures such as in East Asia and Latin America. Similarly, our results would also help managers in the traditionally interdependent cultures in East Asia and other parts of the world, to identify and recruit suitable candidates for their growing multicultural markets and workplaces. 


\section{LIMITATIONS AND FUTURE RESEARCH}

Our research has a few limitations that future research may address. First, we collected the data for this study from a single industry (construction) and a single company (albeit from its branch offices and operating units around the world), hence we would need to be cautious in interpreting the results of this study and replicate them with samples from other organizations and industries in order to test the generalizability of our conceptual model. Second, in this study we focus only on two links, namely service climate $\rightarrow$ internal service quality and internal service quality $\rightarrow$ employee performance, based on service-profit chain. Hence, we need more research to test the impact of these variables on the downstream elements of the Service-Profit Chain, such as employee satisfaction and loyalty, customer satisfaction and profitability etc.

Third, due to concerns about parsimony, we examined the impact of only two (i.e., independence and interdependence) out of Sharma's (2010) ten personal cultural orientations and excluded the other eight (i.e., power, social inequality, masculinity, gender equality, risk aversion, ambiguity intolerance, tradition and prudence). Therefore, we were not able to test the moderating impact of these other orientations in our model, should these be applicable to other businesses or industries. Future research may address this limitation by including those personal cultural orientations that may be more relevant to their research contexts. 


\section{REFERENCES}

Aiken, L.S. and West, S.G. (1991), Multiple Regression: Testing and Interpreting Interactions, ed., Sage, Thousand Oaks CA.

Anderson, J.C. and Gerbing, D.W. (1988), "Structural equation modeling in practice: A review and recommended two step approach", Psychological Bulletin, Vol. 103 No. May, pp. 411-423.

Bagozzi, R.P. and Yi, Y. (1988), "On the evaluation of structural equation models", Journal of the Academy of Marketing Sciences, Vol. 16 No. 1, pp. 74- 84.

Baron, R.M. and Kenny, D.A. (1986), "The Moderator-Mediator variable in social psychological research: Conceptual, strategic and statistical considerations", Journal of Personality and Social Psychology, Vol. 51 No. 6, pp. 1173-1182.

Bartlett, J.E., Kotrlik, J.W. and Higgins, C.C. (2001), "Organizational research: Determining appropriate sample size in survey research appropriate sample size in survey research", Information technology, learning, and performance journal, Vol. 19 No. 1, pp. 43-50.

Berry, L.L. (1981), "The employee as customer", Journal of retail banking, Vol. 3 No. 1, pp. 33 40.

Bond, M.H. (1988), "Finding universal dimensions of individual variation in multi-cultural studies of values: The Rokeach and Chinese value surveys", Journal of Personality and Social Psychology, Vol. 55 No. 6, pp. 1009-1015.

Borman, W.C. and Motowidlo, S.J. (1997), "Task performance and contextual performance: The meaning for personnel selection research", Human Performance, Vol. 10 No. 2, pp. 99109.

Bowen, D.E. and Schneider, B. (2014), "A service climate synthesis and future research agenda", Journal of Service Research, Vol. 17 No. 1, pp. 5-22.

Brooks, R.F., Lings, I.N. and Botschen, M.A. (1999), "Internal marketing and customer driven wavefronts", Service Industries Journal, Vol. 19 No. 4, pp. 49-67.

Bruhn, M. (2003), "Internal service barometers: Conceptualization and empirical results of a pilot study in Switzerland", European Journal of Marketing, Vol. 37 No. 9, pp. 11871204.

Carroll, G.R. and Harrison, J.R. (1998), "Organizational demography and culture: Insights from a formal model and simulation", Administrative Science Quarterly, Vol. 43 No. 3, pp. 637-667.

Chen, W.-J. (2013), "Factors influencing internal service quality at international tourist hotels", International Journal of Hospitality Management, Vol. 35 No. 1, pp. 152-160. 
Chiang, C.-F. and Wu, K.-P. (2014), "The influences of internal service quality and job standardization on job satisfaction with supports as mediators: flight attendants at branch workplace", The International Journal of Human Resource Management, Vol. 25 No. 19, pp. 2644-2666.

Donthu, N. and Yoo, B. (1998), "Cultural influences on service quality expectations", Journal of Service Research, Vol. 1 No. 2, pp. 178-186.

Edvardsson, B., Larsson, G. and Setterlind, S. (1997), "Internal service quality and the psychosocial work environment: an empirical analysis of conceptual interrelatedness", Service Industries Journal, Vol. 17 No. 2, pp. 252-263.

Ehrhart, K.H., Witt, L.A., Schneider, B. and Perry, S.J. (2011), "Service Employees Give as They Get: Internal Service as a Moderator of the Service Climate - Service Outcomes Link", Journal of Applied Psychology, Vol. 96 No. 2, pp. 423-431.

Feldman, S. (1991), "Keeping the Customer Satisfied - Inside and Out", Management Review, Vol. 80 No. 11, pp. 58-60.

Fornell, C. and Larcker, D.F. (1981), "Evaluating Structural Equation Models with Unobservable Variables and Measurement Error", Journal of Marketing Research, Vol. 18 No. 1, pp. 39-50.

Frost, F.A. and Kumar, M. (2000), "INTSERVQUAL-an internal adaptation of the GAP model in a large service organisation", Journal of Services Marketing, Vol. 14 No. 5, pp. 358377.

Furrer, O., Liu, B.S.-C. and Sudharshan, D. (2000), "The Relationships Between Culture and Service Quality Perceptions: Basis for Cross-cultural Market Segmentation and Resource Allocation", Journal of Service Research, Vol. 2 No. 4, pp. 355-371.

George, W.R. (1990), "Internal marketing and organizational behavior: a partnership in developing customer-conscious employees at every level", Journal of Business Research, Vol. 20 No. 1, pp. 63-70.

Grönroos, C. (1981), Internal marketing-an integral part of marketing theory. Marketing of Services. Chicago, IL: J.H. Donnelly

W.E. George, pp. 236-238.

Grönroos, C. (1985), Internal marketing - theory and practice. In: Bloch, T.M., Upah, G.D. and Zeithaml, V.A. (eds.) Services Marketing in a Changing Environment. American Marketing Association, pp. 41-47.

Heskett, J.L., Jones, T.O., Loveman, G.W., Sasser, W.E.J. and Schlesinger, L.A. (1994), "Putting the service-profit chain to work", Harvard Business Review, Vol. 72 No. 2, pp. 164-174.

Heskett, J.L., Sasser, W.E. and Wheeler, J. (2013), The Ownership Quotient: putting the service profit chain to work for unbeatable competitive advantage, ed., Harvard Business Press. 
Hofstede, G. (1980), Culture’s Consequences: International Differences in Work-related Values, ed., Sage Publications, Beverly Hills, CA.

Hofstede, G. (1991), Cultures and Organizations: Software of the Mind ed., McGraw-Hill, London, UK.

Hofstede, G. (2001), Culture's consequences: comparing values, behaviors, institutions, and organizations across nations, 2nd ed., Sage Publications, Thousand Oaks, CA.

Homburg, C., Wieseke, J. and Hoyer, W.D. (2009), "Social identity and the service-profit chain", Journal of Marketing, Vol. 73 No. 2, pp. 38-54.

Hong, Y., Liao, H., Hu, J. and Jiang, K. (2013), "Missing link in the service profit chain: A metaanalytic review of the antecedents, consequences, and moderators of service climate", Journal of Applied Psychology, Vol. 98 No. 2, pp. 237.

Iacobucci, D., Saldanha, N. and Deng, X. (2007), "A Meditation on Mediation: Evidence That Structural Equations Models Perform Better Than Regressions", Journal of Consumer Psychology, Vol. 17 No. 2, pp. 140-154.

Jeng, D.J.-F. and Kuo, S.F.-W. (2012), "Internal service quality within the different Chinese subcultures: a comparison between Taiwan, China, and Singapore", Service Business, Vol. 6 No. 4, pp. 425-458.

Johnston, R. (2008), "Internal service - barriers, flows and assessment", International Journal of Service Industry Management, Vol. 19 No. 2, pp. 210-231.

Kamakura, W.A., Mittal, V., De Rosa, F. and Mazzon, J.A. (2002), "Assessing the service-profit chain", Marketing science, Vol. 21 No. 3, pp. 294-317.

Kang, G.-D., James, J. and Alexandris, K. (2002), "Measurement of internal service quality: application of the SERVQUAL battery to internal service quality", Managing Service Quality, Vol. 12 No. 5, pp. 278-291.

Karau, S.J. and Williams, K.D. (1993), "Social loafing: A meta-analytic review and theoretical integration", Journal of personality and social psychology, Vol. 65 No. 4, pp. 681-706.

Kotler, P. and Armstrong, G. (1991), Principles of Marketing, ed., Prentice Hall, Englewood Cliffs, NJ.

Lings, I.N. and Brooks, R.F. (1998), "Implementing and Measuring the Effectiveness of Internal Marketing", Journal of Marketing Management, Vol. 14 No. 4, pp. 325-351.

Loveman, G.W. (1998), "Employee satisfaction, customer loyalty, and financial performance an empirical examination of the service profit chain in retail banking", Journal of Service Research, Vol. 1 No. 1, pp. 18-31. 
Martinez - Tur, V., Tordera, N., Peiro, J.M. and Potocnik, K. (2011), "Linking Service Climate and Disconfirmation of Expectations as Predictors of Customer Satisfaction: A Cross Level Study1", Journal of Applied Social Psychology, Vol. 41 No. 5, pp. 1189-1213.

Mattila, A.S. (1999), "The Role of Culture in the Service Evaluation Process", Journal of Service Research, Vol. 1 No. 3, pp. 250-261.

Mattila, A.S. and Patterson, P.G. (2004), "Service Recovery and Fairness Perceptions in Collectivist and Individualist Contexts", Journal of Service Research, Vol. 6 No. 4, pp. 336-346.

Miao, C.F., Hughes, D.E., Richards, K.A. and Fu, F.Q. (2015), "Understanding the interactive effects of service climate and transactional sales climate on service quality and sales performance", Journal of the Academy of Marketing Science, Vol. No., pp. 1-17.

Mokhtaran, M., Fakharyan, M., Jalilvand, M.R. and Mohebi, M. (2015), "The Effect of Service Climate on Perceived Service Value and Behavioral Intentions: The Mediating Role of Service Quality", Asia Pacific Journal of Tourism Research, Vol. 20 No. 4, pp. 472-486.

Motowidlo, S.J. and Van Scotter, J.R. (1994), "Evidence that task performance should be distinguished from contextual performance", Journal of Applied Psychology, Vol. 79 No. 4, pp. 475-480.

Nazeer, S., Zahid, M.M. and Azeem, M.F. (2014), "Internal Service Quality and Job Performance: Does Job Satisfaction Mediate?", Journal of Human Resources, Vol. 2 No. 1, pp. 41-65.

Pantouvakis, A. (2011), "Internal service quality and job satisfaction synergies for performance improvement: Some evidence from a B2B environment", Journal of Targeting, Measurement and Analysis for Marketing, Vol. 19 No. 1, pp. 11-22.

Piercy, N. and Morgan, N. (1991), "Internal marketing-The missing half of the marketing programme", Long Range Planning, Vol. 24 No. 2, pp. 82-93.

Podsakoff, P.M., MacKenzie, S.B., Lee, J.-Y. and Podsakoff, N.P. (2003), "Common Method Biases in Behavioral Research: A Critical Review of the Literature and Recommended Remedies", Journal of Applied Psychology, Vol. 88 No. 5, pp. 879-903.

Preacher, K.J., Rucker, D.D. and Hayes, A.F. (2007), "Addressing moderated mediation hypotheses: Theory, methods, and prescriptions", Multivariate behavioral research, Vol. 42 No. 1, pp. 185-227.

Rafiq, M. and Ahmed, P.K. (1993), "The scope of internal marketing: defining the boundary between marketing and human resource management", Journal of Marketing Management, Vol. 9 No. 3, pp. 219-232.

Reynoso, J. and Moores, B. (1995), "Towards the measurement of internal service quality", International Journal of Service Industry Management, Vol. 6 No. 3, pp. 64-83. 
Schneider, B. (1973), "The perception of organizational climate: The customer's view", Journal of Applied Psychology, Vol. 57 No. 3, pp. 248-256.

Schneider, B. (1980), "The Service Organization: Climate Is Crucial", Organizational Dynamics, Vol. 9 No. 2, pp. 52-65.

Schneider, B. (1990), The climate for service: An application of the climate construct. In: Schneider, B. (ed.) Organizational climate and culture. Jossey-Bass, pp. 383-412.

Schneider, B. and Bowen, D.E. (1985), "Employee and Customer Perceptions of Service in Banks: Replication and Extension", Journal of Applied Psychology, Vol. 70 No. 3, pp. 423-433.

Schneider, B., Ehrhart, M.G. and Macey, W.H. (2013), "Organizational climate and culture", Annual review of psychology, Vol. 64 No., pp. 361-388.

Schneider, B., Ehrhart, M.G., Mayer, D.M., Saltz, J.L. and Niles-Jolly, K. (2005), "Understanding organization-customer links in service settings", Academy of Management Journal, Vol. 48 No. 6, pp. 1017-1032.

Schneider, B., Macey, W.H., Lee, W.C. and Young, S.A. (2009), "Organizational Service Climate Drivers of the American Customer Satisfaction Index (ACSI) and Financial and Market Performance", Journal of Service Research, Vol. 12 No. 1, pp. 3-14.

Schneider, B., Macey, W.H. and Young, S.A. (2006), "The climate for service: A review of the construct with implications for achieving CLV goals", Journal of Relationship Marketing, Vol. 5 No. 2-3, pp. 111-132.

Schneider, B., Parkington, J.P. and Buxton, V.M. (1980), "Employee and Customer Perceptions of Service in Banks", Administrative Sciences Quarterly, Vol. 25 No. 2, pp. 252-257.

Schneider, B., Salvaggio, A.N. and Subirats, M. (2002), "Climate strength: a new direction for climate research", Journal of Applied Psychology, Vol. 87 No. 2, pp. 220.

Schneider, B., Wheeler, J.K. and Cox, J.F. (1992), "A passion for service: Using content analysis to explicate service climate themes", Journal of Applied Psychology, Vol. 77 No. 5, pp. 705-716.

Schneider, B., White, S.S. and Paul, M.C. (1998), "Linking service climate and customer perceptions of service quality: Tests of a causal model", Journal of Applied Psychology, Vol. 83 No. 2, pp. 150-163.

Schwartz, S.H. (1994), Beyond individualism/collectivism: New cultural dimensions of values. In: Kim, U., Triandis, H.C., Kagitcibasi, C., Choi, S. and Yoon, G. (eds.) Individualism and collectivism: Theory, method, and applications. Thousand Oaks, CA: Sage, pp. 85119. 
Schwartz, S.H., Melech, G., Lehmann, A., Burgess, S., Harris, M. and Owens, V. (2001),

"Extending the Cross-Cultural Validity of the Theory of Basic Human Values with a

Different Method of Measurement", Journal of Cross-Cultural Psychology, Vol. 32 No. 5, pp. 519-542.

Sharma, P. (2010), "Measuring Personal Cultural Orientations: Scale Development and Validation", Journal of the Academy of Marketing Science, Vol. 38 No. 6, pp. 787-806.

Sharma, P., Chen, I.S.N. and Luk, S.T.K. (2012), "Exploring the Role of IND-COL as a Moderator in the Comprehensive Service Evaluation Model", Journal of International Consumer Marketing, Vol. 24 No. 1-2, pp. 129-142.

Sharma, P., Tam, J.L.M. and Kim, N. (2009), "Demystifying Intercultural Service Encounters: Toward a Comprehensive Conceptual Framework", Journal of Service Research, Vol. 12 No. 2, pp. 227-242.

Sharma, P., Tam, J.L.M. and Kim, N. (2012), "Intercultural Service Encounters (ICSE) Framework: Extension and Empirical Validation", Journal of Services Marketing, Vol. 26 No. 7, pp. 521-534.

Sharma, P., Tam, J.L.M. and Kim, N. (2015), "Service Role and Outcome as Moderators in Intercultural Service Encounters", Journal of Service Management, Vol. 26 No. 1, pp. $137-155$.

Silvestro, R. and Cross, S. (2000), "Applying the service profit chain in a retail environment: Challenging the "satisfaction mirror"", International Journal of Service Industry Management, Vol. 11 No. 3, pp. 244-268.

Smith, P.B., Dugan, S. and Trompenaars, F. (1996), "National culture and the values of organizational employees: A dimensional analysis across 43 nations", Journal of CrossCultural Psychology, Vol. 27 No. 2, pp. 231-264.

Sobel, M.E. (1982), Asymptotic Confidence Intervals for Indirect Effects in Structural Equation Models. In: Leinhart, S. (ed.) Sociological Methodology. San Francisco, CA: Jossey-Bass, pp. 290-312.

Spiller, S.A., Fitzsimons, G.J., Lynch Jr, J.G. and McClelland, G.H. (2013), "Spotlights, floodlights, and the magic number zero: Simple effects tests in moderated regression", Journal of Marketing Research, Vol. 50 No. 2, pp. 277-288.

Stauss, B. (1995), "Internal services: classification and quality management", International Journal of Service Industry Management, Vol. 6 No. 2, pp. 62-78.

Steenkamp, J.-B.E.M. (2001), "The role of national culture in international marketing research", International Marketing Review, Vol. 18 No. 1, pp. 30-44. 
Testa, M.R. and Mueller, S.L. (2009), "Demographic and cultural predictors of international service worker job satisfaction", Managing Service Quality: An International Journal, Vol. 19 No. 2, pp. 195-210.

Trompenaars, F. (1993), Riding the Waves of Culture, ed., The Economists Books, London, UK.

Werner, J.M. (1994), "Dimensions that make a difference: Examining the impact of in-role and extrarole behaviors on supervisory ratings", Journal of Applied Psychology, Vol. 79 No. 1, pp. 98-107.

Young, J.A. and Varble, D.L. (1997), "Purchasing's performance as seen by its internal customers: a study in a service organization", International Journal of Purchasing and Materials Management, Vol. 33 No. 2, pp. 36-41.

Zhang, R.Y., Liu, X.M., Wang, H.Z. and Shen, L. (2011), "Service climate and employee service performance: exploring the moderating role of job stress and organizational identification", The Service Industries Journal, Vol. 31 No. 14, pp. 2355-2372. 
Figure 1 - Conceptual Model

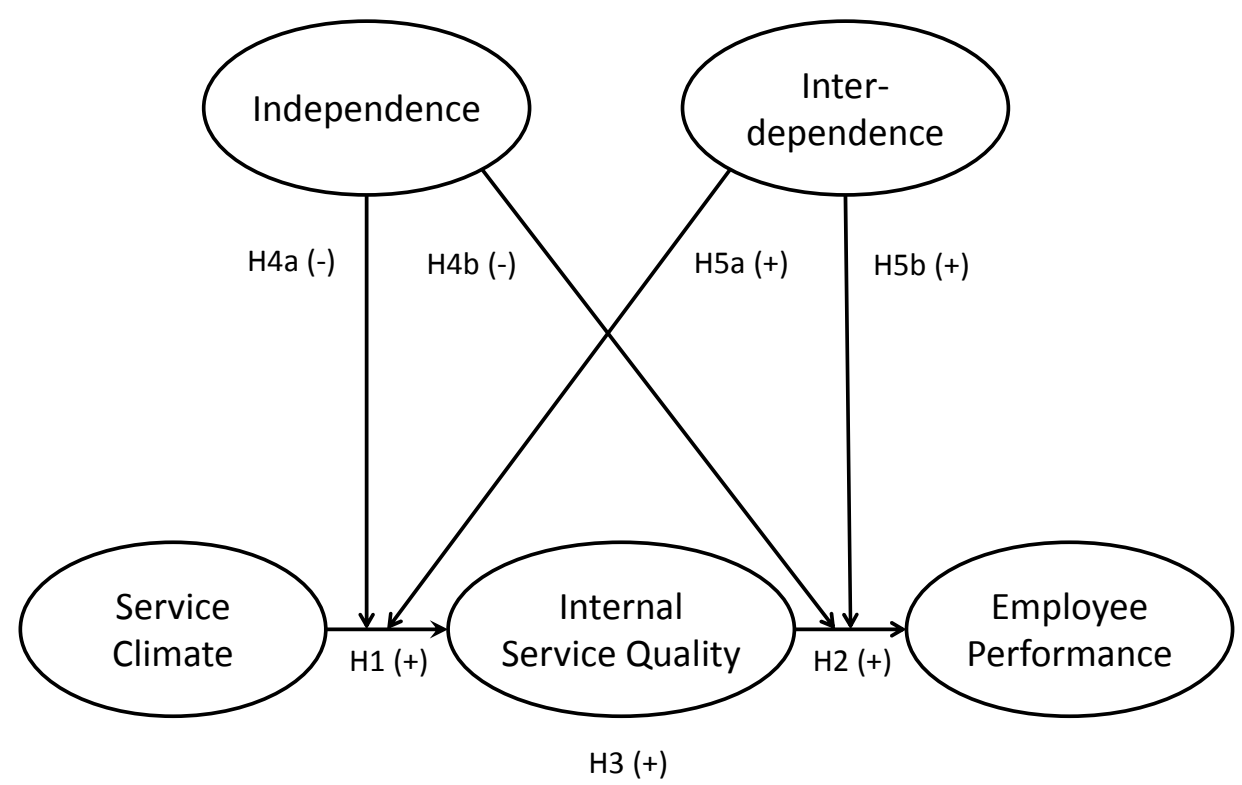


Figure 2 - Moderated Mediation Model based on Preacher et al. (2007)

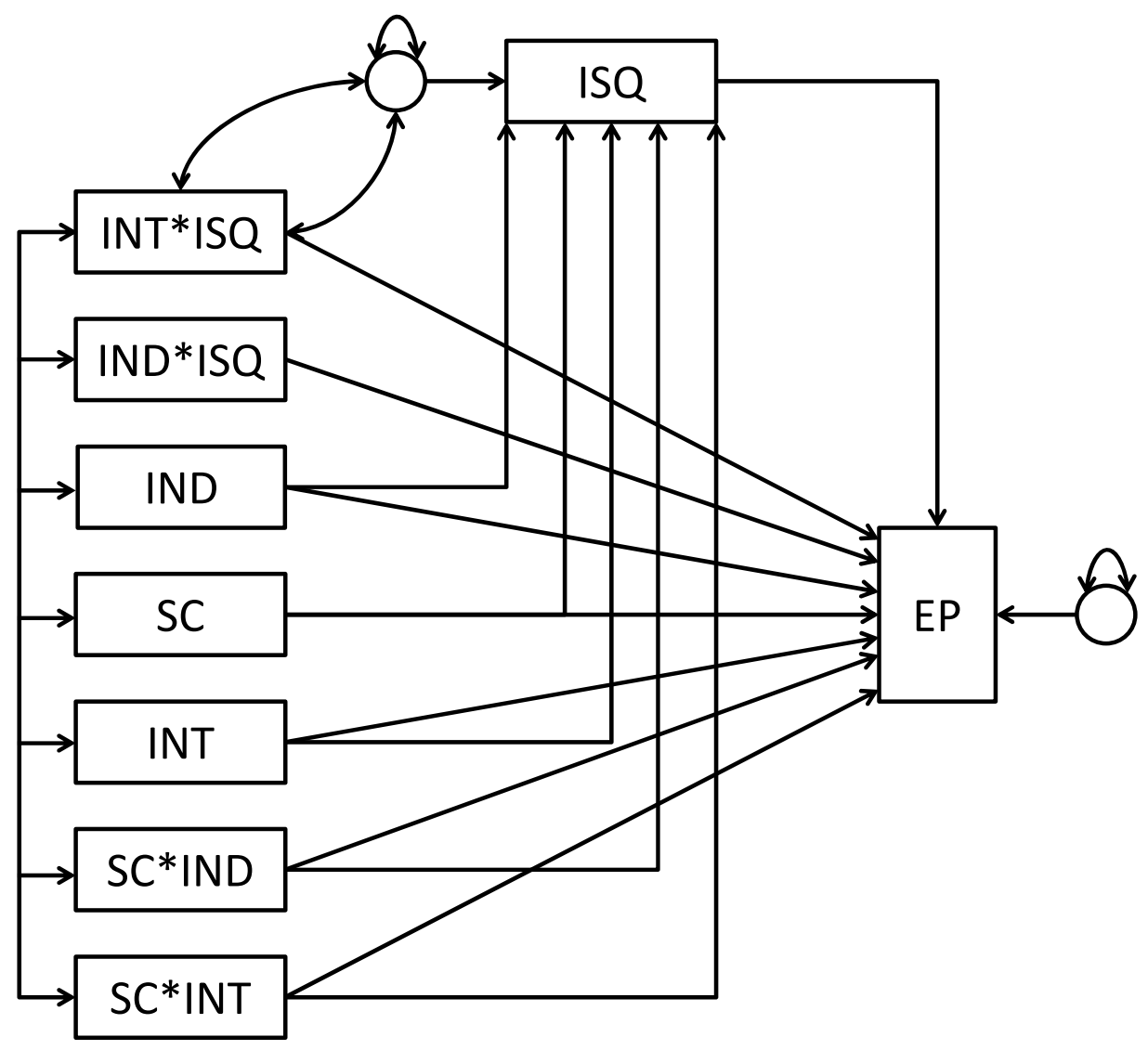


Table 1 - Respondent Demographics $(\mathrm{N}=353)$

\begin{tabular}{|c|c|c|}
\hline Demographic Variables & Frequency & Percentage \\
\hline \multicolumn{3}{|l|}{ Gender } \\
\hline Male & 305 & $86.4 \%$ \\
\hline Female & 48 & $13.6 \%$ \\
\hline \multicolumn{3}{|l|}{ Current Role } \\
\hline Site Supervisor & 43 & $12.2 \%$ \\
\hline Administration / Finance / Accounts & 30 & $8.5 \%$ \\
\hline Design / Quality Engineer & 52 & $14.7 \%$ \\
\hline Project Engineer / Manager & 132 & $37.4 \%$ \\
\hline Contract Manager & 9 & $2.5 \%$ \\
\hline Department / Division Manager & 45 & $12.7 \%$ \\
\hline Purchase & 20 & $5.7 \%$ \\
\hline Others (e.g., IT, HR, etc.) & 22 & $6.2 \%$ \\
\hline \multicolumn{3}{|l|}{ Education } \\
\hline Secondary School & 36 & $10.2 \%$ \\
\hline Diploma & 122 & $34.6 \%$ \\
\hline Bachelor's Degree & 191 & $54.1 \%$ \\
\hline Master's Degree and above & 4 & $1.1 \%$ \\
\hline \multicolumn{3}{|l|}{ Current Tenure } \\
\hline$<2$ years & 151 & $42.8 \%$ \\
\hline 2 to 5 years & 100 & $28.3 \%$ \\
\hline 6 to 10 years & 57 & $16.1 \%$ \\
\hline 11 to 15 years & 15 & $4.2 \%$ \\
\hline 16 to 20 years & 18 & $5.1 \%$ \\
\hline$>20$ years & 12 & $3.4 \%$ \\
\hline \multicolumn{3}{|l|}{ Total Work Experience } \\
\hline$<2$ years & 56 & $15.9 \%$ \\
\hline 2 to 5 years & 95 & $26.9 \%$ \\
\hline 6 to 10 years & 70 & $19.8 \%$ \\
\hline 11 to 15 years & 40 & $11.3 \%$ \\
\hline 16 to 20 years & 41 & $11.6 \%$ \\
\hline$>20$ years & 51 & $14.4 \%$ \\
\hline \multicolumn{3}{|l|}{ Overseas Experience } \\
\hline None & 251 & $71.1 \%$ \\
\hline$<2$ years & 45 & $12.7 \%$ \\
\hline 2 to 5 years & 29 & $8.2 \%$ \\
\hline 6 to 10 years & 12 & $3.4 \%$ \\
\hline 11 to 15 years & 9 & $2.5 \%$ \\
\hline 16 to 20 years & 6 & $1.7 \%$ \\
\hline$>20$ years & 1 & $0.3 \%$ \\
\hline
\end{tabular}


Table 2 - Descriptive Statistics

Composite Service Climate (Schneider et al. 1998)

$(1=$ Strongly disagree, $7=$ Strongly agree $)$

CO1 Management of our company does a good job keeping customers informed of changes which affect them.

$\begin{array}{llll}4.98 & 1.00 & .81 & .65\end{array}$

Top Management of our company has a plan to improve the quality of our work and service.

$\begin{array}{llll}5.05 & 1.12 & .78 & .61\end{array}$

Our management is very committed to improving the quality of our area's work and service.

$\begin{array}{llll}5.29 & 1.10 & .80 & .64\end{array}$

Our management recognizes and appreciates high quality work and service.

$\begin{array}{llll}5.16 & 1.09 & .81 & .65\end{array}$

Management of our company asks external customers to evaluate the quality of our work and service.

$\begin{array}{llll}5.16 & 1.11 & .97 & .93\end{array}$

We are informed about external customers' evaluations

of the quality of work and service delivered.

$\begin{array}{llll}5.06 & 1.14 & .87 & .75\end{array}$

Global Service Climate (Schneider et al. 1998)

$(1=$ Very poor, $7=$ Excellent $)$

GSC1 Job knowledge and skills of employees in our business to deliver superior quality work and service?

Efforts to measure and track the quality of work and

GSC2 service provided by the company.

$\begin{array}{llll}4.34 & 1.20 & .81 & .65\end{array}$

The recognition and rewards that employees receive for

GSC3

the delivery of superior work and service.

$\begin{array}{llll}5.04 & .94 & .84 & .71\end{array}$

GSC4 The leadership shown by the management in supporting the service quality effort.

$\begin{array}{llll}4.97 & 1.12 & .82 & .67\end{array}$

The effectiveness of communication effort provided to both employees and customers by our company.

$\begin{array}{llll}4.81 & 1.08 & .77 \quad .60\end{array}$

Tools, technology, and other resources provided by our

GSC6 company to support the delivery of superior quality of work and service.

\section{Internal Service Quality (Bruhn 2003)}

How would you rate the service provided by other departments/operating units on the following criteria? $(1=$ Very poor, $7=$ Excellent $)$

ISQ1 Competence

ISQ2 Reliability

$\begin{array}{llll}4.78 & 1.12 & .84 & .70\end{array}$

ISQ3 Accessibility

4.77

$\begin{array}{lll}1.13 & .90 & .80\end{array}$

ISQ4 Friendliness

$\begin{array}{llll}4.88 & 1.23 & .73 & .53\end{array}$

ISQ5 Reaction speed

$\begin{array}{llll}4.57 & 1.18 & .86 & .74\end{array}$

ISQ6 Time to provide the service

$\begin{array}{llll}4.48 & 1.21 & .86 & .75\end{array}$


ISQ7 Flexibility

ISQ8 Customization

ISQ9 Added-value generated

ISQ10 Cost-benefit ratio

ISQ1 1 Transparency in service offered

ISQ12 Cost transparency
4.64

4.47

4.38

4.26

4.40

4.29 $\begin{array}{ll}1.26 & .87\end{array}$

$1.18 \quad .86$

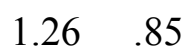

$1.27 \quad .83$

$1.36 \quad .85$

$1.28 \quad .84$
.75

.73

.72

.68

.72

.71

\section{Employee Performance (Werner 1994)}

How would you rate this employee on the following?

$(1=$ Very poor, $7=$ Excellent $)$

\section{In-role Behaviors}

EP1 Job knowledge

$\begin{array}{llll}5.15 & 1.12 & .80 & .64\end{array}$

EP2 Accuracy of work

$\begin{array}{llll}5.21 & 1.14 & .80 & .63\end{array}$

EP3 Productivity

EP4 Ability to organize work

$\begin{array}{llll}5.25 & 1.24 & .88 & .78\end{array}$

$\begin{array}{llll}4.94 & 1.16 & .81 & .65\end{array}$

Extra-role Behaviors

EP5 Dependability

$\begin{array}{llll}5.10 & 1.28 & .86 & .74\end{array}$

EP6 Following policies and procedures

$\begin{array}{llll}5.20 & 1.14 & .64 & .41\end{array}$

EP7 Initiative

$\begin{array}{llll}4.76 & 1.27 & .82 & .68\end{array}$

EP8 Team work

$\begin{array}{llll}5.27 & 1.20 & .74 & .52\end{array}$

Overall Employee Performance

OEP Overall performance over the past year

$\begin{array}{llll}5.22 & 1.08 & \mathrm{NA} & \mathrm{NA}\end{array}$

\section{Personal Cultural Orientations (Sharma 2010)}

$(1=$ Strongly disagree, $7=$ Strongly agree $)$

\section{Independence}

IND1 I would rather depend on myself than others.

$\begin{array}{llll}4.46 & 1.54 & .75 & .56\end{array}$

My personal identity, independent of other, is important to me.

$\begin{array}{llll}4.58 & 1.46 & .91 & .84\end{array}$

$\begin{array}{llll}4.35 & 1.39 & .96 & .91\end{array}$

$\begin{array}{llll}4.76 & 1.37 \quad .73 & .54\end{array}$

IND3 I rely on myself most of the time, rarely on others.

$\begin{array}{llll}4.52 & 1.31 & .76 & .56\end{array}$

IND5 I enjoy being unique and different from others in many respects.

\section{Interdependence}

INT1 The well-being of my group members is important for me.

INT2 I feel good when I cooperate with my group members.

$\begin{array}{llll}4.66 & 1.11 & .92 & .84\end{array}$

INT3 It is my duty to take care of my family members, whatever it takes.

$\begin{array}{llll}5.03 & 1.04 & .72 & .52\end{array}$

Family members should stick together, even if they do

INT4 not agree.

$\begin{array}{llll}4.30 & 1.35 & .80 & .64\end{array}$

INT5 I enjoy spending time with my group members.

$\begin{array}{llll}4.40 & 1.07 & .71 & .50\end{array}$


Table 3 - Correlations Table

\begin{tabular}{|c|c|c|c|c|c|c|c|c|c|}
\hline Construct & Mean & SD & CSC & GSC & ISQ & ESP & OEP & IND & INT \\
\hline Composite Service Climate (CSC) & 5.12 & .86 & 1.00 & & & & & & \\
\hline Global Service Climate (GSC) & 4.83 & .86 & $.75^{* * *}$ & 1.00 & & & & & \\
\hline Internal service quality (ISQ) & 4.56 & 1.05 & $.54^{* * *}$ & $.61^{* * *}$ & 1.00 & & & & \\
\hline Employee Service Performance (ESP) & 5.08 & 1.01 & $.28^{* *}$ & $.26^{* *}$ & $.36^{* *}$ & 1.00 & & & \\
\hline Overall Employee Performance (OEP) & 5.22 & 1.08 & $.26^{* *}$ & $.25^{* *}$ & $.30^{* *}$ & $.84^{* * *}$ & 1.00 & & \\
\hline Independence (IND) & 4.53 & 1.18 & $.10^{*}$ & .09 & .00 & $.13^{*}$ & .08 & 1.00 & \\
\hline Interdependence (INT) & 4.59 & .92 & $.33^{* *}$ & $.26^{* *}$ & $.33^{* *}$ & $.23^{* *}$ & $.24^{* *}$ & -.03 & 1.00 \\
\hline Composite Reliability & - & - & .87 & .89 & .96 & .92 & NA & .89 & .86 \\
\hline Average Variance Extracted & - & - & .71 & .64 & .71 & .63 & NA & .64 & .68 \\
\hline
\end{tabular}


Table 4 - Mediation Analysis (Iacobucci et al. 2007)

\begin{tabular}{|c|c|c|c|c|}
\hline \multirow{2}{*}{$\begin{array}{l}\text { Dependent } \\
\text { Variable } \rightarrow \\
\text { Independent } \\
\text { Variable } \rightarrow\end{array}$} & \multicolumn{2}{|c|}{$\begin{array}{l}\text { Employee Service } \\
\text { Performance (ESP) }\end{array}$} & \multicolumn{2}{|c|}{$\begin{array}{l}\text { Overall Employee } \\
\text { Performance (OEP) }\end{array}$} \\
\hline & $\begin{array}{c}\text { Global } \\
\text { Service } \\
\text { Climate } \\
\text { (GSC) }\end{array}$ & $\begin{array}{c}\text { Composite } \\
\text { Service } \\
\text { Climate } \\
\text { (CSC) }\end{array}$ & $\begin{array}{c}\text { Global } \\
\text { Service } \\
\text { Climate } \\
\text { (GSC) }\end{array}$ & $\begin{array}{c}\text { Composite } \\
\text { Service } \\
\text { Climate } \\
\text { (CSC) }\end{array}$ \\
\hline $\mathrm{H} 1: \mathrm{SC} \rightarrow \mathrm{ISQ}$ & $.68^{* * *}$ & $.63^{* * *}$ & $.68^{* * *}$ & $.64^{* * *}$ \\
\hline $\mathrm{H} 2: \mathrm{ISQ} \rightarrow \mathrm{EP}$ & $.22^{* *}$ & $.20^{* *}$ & $.26^{* *}$ & $.23^{* *}$ \\
\hline $\mathrm{SC} \rightarrow \mathrm{EP}$ & .08 & $.16^{*}$ & .10 & $.15^{*}$ \\
\hline$z$-statistic & $2.65^{* *}$ & $2.42^{*}$ & $3.32^{* * *}$ & $1.99^{*}$ \\
\hline$\chi^{2}$-value & 334.09 & 397.77 & 212.34 & 215.92 \\
\hline$d f$ & 186 & 182 & 103 & 98 \\
\hline$\chi^{2} / d f$ & 1.79 & 2.19 & 2.06 & 2.20 \\
\hline CFI & .98 & .97 & .98 & .97 \\
\hline NFI & .96 & .95 & .96 & .95 \\
\hline RMSEA & .037 & .042 & .030 & .045 \\
\hline SRMR & .048 & .058 & .055 & .066 \\
\hline
\end{tabular}


Table 5 - Moderated Mediation Analysis (Preacher et al. 2007)

\begin{tabular}{|c|c|c|c|c|}
\hline \multirow{2}{*}{$\begin{array}{l}\text { Dependent } \\
\text { Variable } \rightarrow \\
\text { Independent } \\
\text { Variable } \rightarrow\end{array}$} & \multicolumn{2}{|c|}{$\begin{array}{l}\text { Employee Service } \\
\text { Performance (ESP) }\end{array}$} & \multicolumn{2}{|c|}{$\begin{array}{l}\text { Overall Employee } \\
\text { Performance (OEP) }\end{array}$} \\
\hline & $\begin{array}{c}\text { Global } \\
\text { Service } \\
\text { Climate } \\
\text { (GSC) }\end{array}$ & $\begin{array}{c}\text { Composite } \\
\text { Service } \\
\text { Climate } \\
\text { (CSC) }\end{array}$ & $\begin{array}{c}\text { Global } \\
\text { Service } \\
\text { Climate } \\
\text { (GSC) }\end{array}$ & $\begin{array}{c}\text { Composite } \\
\text { Service } \\
\text { Climate } \\
\text { (CSC) }\end{array}$ \\
\hline $\mathrm{H} 1: \mathrm{SC} \rightarrow \mathrm{ISQ}$ & $.66^{* * *}$ & $.63^{* * *}$ & $.62^{* * *}$ & $.59^{* * *}$ \\
\hline H2: ISQ $\rightarrow$ EP & $.18^{* *}$ & $.20^{* * *}$ & $.25^{* * *}$ & $.21^{* * *}$ \\
\hline $\mathrm{SC} \rightarrow \mathrm{EP}$ & .06 & .08 & .04 & .10 \\
\hline H4a: SC*IND & $-.16^{* *}$ & $-.18^{* *}$ & $-.19^{* * *}$ & $-.17^{* *}$ \\
\hline H4b: SC*INT & $.15^{* *}$ & $.13^{*}$ & $.14^{* *}$ & $.13^{*}$ \\
\hline H5a: IND*ISQ & $-.21^{* * *}$ & $-.17^{* *}$ & $-.22^{* * *}$ & $-.15^{* *}$ \\
\hline H5b: INT*ISQ & $.17^{* *}$ & $.15^{* *}$ & $.14^{* *}$ & $.19^{* * *}$ \\
\hline$\chi^{2}$-value & 515.08 & 578.15 & 399.89 & 386.36 \\
\hline$d f$ & 251 & 248 & 189 & 166 \\
\hline$\chi^{2} / d f$ & 2.05 & 2.33 & 2.12 & 2.33 \\
\hline CFI & .96 & .95 & .97 & .96 \\
\hline NFI & .94 & .93 & .95 & .94 \\
\hline RMSEA & .042 & .044 & .034 & .038 \\
\hline SRMR & .061 & .064 & .056 & .061 \\
\hline
\end{tabular}


Table 6 - Spotlight Analysis (Spiller et al. 2013)

\begin{tabular}{|c|c|c|c|c|c|c|}
\hline \multirow[t]{2}{*}{$\begin{array}{l}\text { Moderator } \\
\text { Variable } \rightarrow\end{array}$} & \multicolumn{3}{|c|}{ Independence (IND) } & \multicolumn{3}{|c|}{ Interdependence (INT) } \\
\hline & M - 1 SD & $\mathbf{M}$ & $\mathrm{M}+1 \mathrm{SD}$ & M - 1 SD & $\mathbf{M}$ & $\mathrm{M}+1 \mathrm{SD}$ \\
\hline $\mathrm{SC} \rightarrow \mathrm{ISQ}$ & $.69^{* * *}$ & $.66^{* * *}$ & $.53^{* * *}$ & $.55^{* * *}$ & $.66^{* * *}$ & $.72^{* * *}$ \\
\hline ISQ $\rightarrow$ EP & $.25^{* * *}$ & $.18^{* *}$ & $.13^{*}$ & $.14^{* *}$ & $.18^{* *}$ & $.24^{* * *}$ \\
\hline $\mathrm{SC} \rightarrow \mathrm{EP}$ & .04 & .06 & .09 & .10 & .06 & .02 \\
\hline SC*IND & $-.18^{* *}$ & $-.16^{* *}$ & -.10 & $-.13^{*}$ & $-.16^{* *}$ & $-.12^{*}$ \\
\hline SC*INT & .11 & $.15^{* *}$ & .12 & $.14^{* *}$ & $.15^{* *}$ & $.20^{* *}$ \\
\hline IND*ISQ & $-.13^{* *}$ & $-.21^{* *}$ & $-.15^{*}$ & -.11 & $-.21^{* * *}$ & $-.14^{*}$ \\
\hline INT*ISQ & .08 & $.17^{* *}$ & .08 & $.15^{* *}$ & $.17^{* *}$ & $.21^{* *}$ \\
\hline
\end{tabular}

